\title{
Do Billboard Advertisements Drive Customer Retention?
}

\section{Expanding the "AIDA" Model to "AIDAR"}

JOHN L. FORTENBERRY, JR.
Louisiana State University
Shreveport
Willis-Knighton Health
System
john.fortenberry@lsus.edu

PETER J. McGOLDRICK

University of Manchester

peter.mcgoldrick@

manchester.ac.uk
Submitted March 14, 2018;

revised August 14, 2018;

accepted October 23, 2018;

published online January 20, 2019.
Many researchers neglect the wider capabilities of billboards. Managers deploy billboards to generate awareness, evaluated through awareness-tracking studies, thus reinforcing their beliefs. This two-part investigation examines assumptions that billboards primarily serve initial attraction roles, early-stage effects in hierarchies such as the Attention-InterestDesire-Action (AIDA) model. Study 1 indicates that billboards also affect existing customers and repatronage decisions. In Study 2, experienced marketing executives recognized billboards' role in assisting reinforcement and customer retention. On the basis of these studies and evidence from related fields, it is timely to suggest a logical progression to AIDAR, which adds "retention" to the AIDA model.

\section{INTRODUCTION}

With increasing audience fragmentation, advertisers face greater challenges as well as new opportunities for communicating with current and prospective customers. This change is due in large part to the proliferation of interactive technologies, which give individuals more choices and, in some cases, the ability to block content selectively. Digital viewing and recording devices make channel zapping and advertisement skipping extremely easy while also reducing the viability of some print media.
Billboard advertising may offer a viable option, because no technologies exist to block delivery of billboard images and messages, although consumers may ignore them if busy with other tasks. Billboards have received criticism, in some cases accused of causing visual pollution and clutter, environmental harm if installers remove vegetation, and possible motorist distraction (Scenic America, 2017; Vespe, 1997). Others have expressed concerns regarding billboards that advertised potentially harmful products, with associated public-health impacts, particularly among disadvantaged

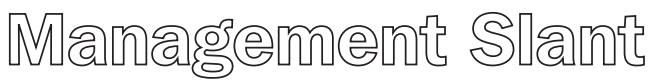

- Contrary to enduring beliefs, billboards can be effective across the hierarchy of effects, including customer-retention roles that are missing from traditional advertising typologies.

- Combined with billboards' resilience against blocking, this effectiveness substantially broadens their potential, increasing utility to executives seeking to influence existing customers.

- A regional billboard campaign provides clear indications of billboard influence both on new and on existing customers.

- A national, expert survey of senior marketing-communications managers and directors provides support for billboards' potential to achieve customer-retention aims.

- These studies encourage marketing executives to reevaluate expectations and deployment of billboards, offering further strategic-marketing opportunities. 
communities (Altman, Schooler, and Basil, 1991; Hackbarth, Silvestri, and Cosper, 1995).

Billboards are defined as "large format advertising displays intended for viewing from extended distances, generally more than 50 feet" (Outdoor Advertising Association of America [OAAA], 2016). Use of the medium is widespread, accounting for approximately $\$ 7.6$ billion of advertising expenditures in the United States. Although sales declined briefly during the 2007-2009 recession, the trend of consistent annual growth soon returned, and growth has averaged 3.7 percent annually since 2009 (OAAA, 2016). The medium enjoys a lower cost per thousand views than other mass media, which makes billboard advertising a viable option for reaching regional or national audiences (Moriarty, Mitchell, and Wells, 2015; OAAA, 2016).

Billboards have a long history and still attract increasing investment. A body of academic literature has developed, but there is a need for further investigation of the functions and potential of billboards. Industry sources report trends and cases of billboard campaigns (e.g., OAAA, 2016), but assessments of the full range of billboards' potential effects are limited. Both current and prospective customers usually are advertisers' targets; the former significantly more likely will recognize advertisements (Vaughan, Beal, and Romaniuk, 2016). Billboards' effects on existing customers have not been a main focus of previous research studies, however.

Questions have emerged across the advertising industry regarding levels of consumer receptiveness, given increasing disenfranchisement from efforts to capture their attention, because of the pervasiveness of advertising messages (Elliott and Speck, 1998; Ha and Litman, 1997; Hammer, Riebe, and Kennedy, 2009). Information overload has intensified as advertisers try to break through existing clutter by adding more communication channels (Truong and Simmons, 2010), creating even higher noise levels (Steinberg, 2008). This onslaught of intrusive messages has resulted in consumers walling themselves into their own worlds (Kim, Kim, Yeh, and Choi, 2011), many using technologies to help stem the flow (Mitchell, 2012).

Advertising clutter and goal impediment have become major causes of Internet-advertisement avoidance (Seyedghorban, Tahernejad, and Matanda, 2016). Previous and existing customers are the most accessible targets for such advertising, because companies already have knowledge of their interests and preferences (Bleier and Eisenbeiss, 2015).

An interesting dilemma therefore faces those considering using billboards. On the one hand, billboards are a distinctive medium and thus are able to stand out in an age of advertising clutter, information overload, and active blocking by consumers.

\section{At face value, billboards can deliver desired exposure, but does that exposure result in animosity toward the advertisers using the medium?}

On the other hand, many people are growing weary of commercial appeals that are intrusive to their daily life. At face value, billboards can deliver desired exposure, but does that exposure result in animosity toward the advertisers using the medium? From the managerial perspective, are billboards still valuable, and how versatile are they as advertising platforms? This investigation contributes insights that address these questions and aims to stimulate further research.

This research had several objectives:

- to assess the roles of billboards from both consumer and management perspectives, especially whether billboards influence later stages in the purchase-repurchase hierarchy;

- to examine marketing-management evaluations of billboard attributes, testing effects of these evaluations on management ratings of billboards as a media choice; and

- to propose that the long-established AIDA model of advertising effects requires updating to include customer reinforcement, relating to important reminder and retention effects.

\section{OVERVIEW OF PREVIOUS STUDIES}

Previous academic research on billboards is relatively sparse, given their commercial importance. Key findings are as follows:

- Billboards have the ability to generate recall (Fitts and Hewett, 1977; Hewett, 1972; King and Tinkham, 1989-1990; Osborne and Coleman, 2008).

- Precise location vis-à-vis passersby determines the extent to which billboards will be noticed, on the basis of increasingly sophisticated research techniques (Wilson and Casper, 2016; Wilson and Till, 2011).

- Creative and spatial applications also affect billboardadvertisement recall (Bhargava, Donthu, and Caron, 1994; Donthu, Cherian, and Bhargava, 1993; Young, 1984).

- Billboards are capable of driving sales (Bhargava and Donthu, 1999; Taylor and Franke, 2003).

- Billboards sometimes can reinforce adverse consumption patterns (Altman et al., 1991; Fortenberry and McGoldrick, 2011). 
Although one study reported that billboards maintained brand presence in local markets (Taylor, Franke, and Bang, 2006), researchers generally have neglected postsales effects of billboards in helping to reinforce behavior patterns in positive contexts.

Comparisons of relative media effectiveness have produced mixed and sometimes conflicting results, stemming from the use of different methods, contexts, and criteria. One study found radio more effective than billboards, but with data for only one retailer and three stores (Berkowitz, Allaway, and D'Souza, 2001). Another noted the media efficiency of billboards, with a relatively low minimum cost that also enables high spatial flexibility (Naik, Peters, and Raman, 2008).

Although billboards achieved far higher gross rating points (GRPs) in another study, compared with print and cinema, their awareness advantage appeared less pronounced (Naik et al., 2008). Other researchers have been critical of the limited empirical bases of these studies and examined elasticities of various media (excluding Internet) across 250 established brands of packaged goods. The research yielded mixed findings for billboard elasticities, depending on the models, but the authors concluded that brands using billboards appear "well-informed that this medium works for them" (Frison, Dekimpe, Croux, and De Maeyer, 2014, p. 432).

A study based on large surveys of multiple media and touchpoints across 47 countries reported that brand recall of outdoor advertisements was 1.5 times greater among existing customers than among potential customers (Harrison, 2013, p. 185). This power to attract attention was not limited necessarily to the role of stimulating initial awareness but also could build desire and calls to action among existing customers. Billboards have strong potential to attract attention, because of their physical size, opportunities for high-impact creative treatments, and typically prime locations (Taylor et al., 2006).

The frequent focus on billboard awareness and recall in this literature places most emphasis on the early stages of the advertising hierarchies of effects. This reflects early-stages emphasis

- in AIDA (Strong, 1925),

- in the Defining Advertising Goals for Measured Advertising Results (DAGMAR) model (with awareness-comprehensionconviction-action stages; Colley, 1961), and

- in the influential Cognitive-Affective-Conative (CAC) model (Barry, 1987; Barry and Howard, 1990).

These early models attracted criticisms, primarily for oversimplification and implied rigid sequencing (Ambler, 2000; Cramphorn, 2006; Weilbacher, 2001), yet they remain influential (Barry, 2002).
Management discussions indicate that billboards also can fulfill roles in helping to retain patronage. This extends beyond the action stages of AIDA into assisting reinforcement, as reflected in the Attention-Trial-Reinforcement (ATR) model (Ehrenberg, 1974/2000; Ehrenberg, Barnard, Kennedy, and Bloom, 2002). The ATR model is less inclusive of potential prepurchase stages, however, which might reflect the increase in available sales and loyalty data at the time.

In parallel developments, the Transtheoretical Model (TTM) includes stages of change-precontemplation, contemplation, preparation, action, and maintenance or relapse (Prochaska, Diclemente, and Norcross, 1992)-inclusive of both pre- and postaction stages. Researchers have applied the TTM in numerous areas of psychotherapy (Velicer et al., 1995) and social marketing (Andreasen, 1995). Although developed in different disciplines, both the TTM and the ATR illustrate the major gap in the AIDA model.

Controversies regarding earlier uses of billboards to foster socially undesirable behaviors, such as alcohol consumption and smoking, affirm this postaction maintenance role (Altman et al., 1991; Hackbarth et al., 1995). In other contexts, consumers often seek postpurchase reinforcement of patronage decisions (Ehrenberg, 1974/2000; Solomon, 2017), so billboard images of prestige vehicles or services can reassure and remind existing customers to return to the brand while also helping to create awareness and interest among potential new patrons.

Evaluating both consumer and advertising-management perspectives on the functions of billboards adds to the academic literature on billboard advertising by examining a variety of potential billboard functions for practitioners. This article thus addresses gaps in the billboards literature, leading to further reflection on implications for advertisers and for the potential evolution of the AIDA model.

\section{METHODOLOGY}

\section{Study 1: Consumer Survey}

This study tracked a billboard campaign by a health-system provider promoting urgent-care centers in two neighboring U.S. cities. Urgent-care centers treat patients who generally do not require immediate admission to a hospital emergency department. The provider studied faces direct competition from another urgent-care provider in these cities as well as extensive indirect competition. Hospital emergency departments can provide similar services, but care usually is much more expensive in such settings. General medical clinics also may serve as lower cost substitutes for urgentcare clinics, but they usually operate during more limited hours. The centers that assisted in this study therefore operate in a highly competitive marketplace. 
Table 1 Survey Samples for Studies 1 and 2

\begin{tabular}{|c|c|c|c|c|c|}
\hline \multicolumn{6}{|c|}{ Study 1: Consumer Survey $(n=1,640)$} \\
\hline Gender & $\%$ & Education & $\%$ & Annual Income & $\%$ \\
\hline Female & 63.0 & High school & 34.7 & Under $\$ 25,000$ & 39.1 \\
\hline Male & 37.0 & Some college & 34.6 & $\$ 25,000-\$ 39,999$ & 23.9 \\
\hline Age range & & College degree & 30.6 & $\$ 40,000-\$ 54,999$ & 15.4 \\
\hline Under 30 & 32.9 & Customer type & & $\$ 55,000$ or over & 21.7 \\
\hline $30-49$ & 44.1 & New customer & 46.7 & & \\
\hline 50 or older & 23.0 & Returning customer & 53.3 & & \\
\hline \multicolumn{6}{|c|}{ Study 2: Management Survey $(n=263(241))$} \\
\hline Gender & $\%$ & Status & $\%$ & $\%$ of Advertising Spend & $\%$ \\
\hline Female & 69.5 & VP or CEO & 15.9 & No billboard spend & 13.8 \\
\hline Male & 30.5 & Director & 63.6 & Under 5\% & 18.4 \\
\hline Age range & & Other management & 20.5 & $5 \%-9 \%$ & 23.4 \\
\hline Under 30 & 4.4 & Media-buying activity & & $10 \%-14 \%$ & 18.0 \\
\hline 30-39 & 24.7 & Under 10 years & 28.4 & $15 \%-19 \%$ & 10.0 \\
\hline $40-49$ & 35.6 & 10-19 years & 38.9 & $20 \%$ or more & 16.3 \\
\hline 50 or older & 35.6 & 20 years or longer & 32.5 & & \\
\hline
\end{tabular}

The need for urgent care can occur at any time and usually is a primary driver of customers' visits but not necessarily of their choice of facility. That choice usually requires relatively short decision processes, well within a conventional billboard-campaign span. This one-month campaign used eight stationary large panels, one trivision panel, and seven slightly smaller format posters, overall constituting 133 GRPs. Contents included appropriately placed organization and center logos, which are important for brand recognition if passersby have to view rapidly (Klerkx and Van Meurs, 2006), as well as locations and hours of operation.

Measures. The researchers developed and tested a selfadministered questionnaire for distribution to patients on arrival. The first section of the questionnaire focused on the perceived effects of billboards across a range of effects. The study context limited questionnaire length, precluding the use of multi-item scales. Rossiter (2002) argued and demonstrated that single-item scales can perform equally well for objects that are "easily and uniformly imagined," (Bergkvist and Rossiter, 2007, p. 176) such as billboards.

After establishing whether the respondent had noticed the billboards, the researchers used a 7-point scale (developed from Havlena and Graham, 2004) to measure change in awareness levels. Because these studies were cross-sectional, a multipoint awareness scale (e.g., Yoo, Donthu, and Lee, 2000) offered greater calibration. The authors' scale of advertising informative(ness) builds on a concept developed by previous researchers (Ducoffe, 1995; Smit and
Neijens, 2000). An extent-of-influence scale (adapted from Gilly, Graham, Wolfinbarger, and Yale, 1998) reflected a later stage in the hierarchy for new and existing customers.

Sample. Over the course of the campaign, 2,380 patients presented for treatment, and 1,640 participated in the survey, for a response rate of 68.9 percent. Of these individuals, 1,190 (72.6 percent) had noticed the campaign and so could respond to all of the questions. Female respondents outnumbered male respondents, as the more likely chief caregivers for dependent family members (See Table 1).

On the basis of category midpoints, the respondents had a mean age of 38.5 years and mean annual income of $\$ 37,644$ (individuals, not households). "Returning customers" had visited one of the centers previously, either as a patient or as an accompanying person. Composing 53.3 percent of respondents, they had previous opportunities to evaluate directly the facilities and services.

\section{Study 2: Marketing-Management National Survey}

This study sought a broader range of expert management perspectives from the health-services sector across all regions of the United States. For most constructs, the researchers could deploy multiple items to provide more detailed information on perceived roles and performance of billboards. Attribute-performance and attribute-importance scales for billboards drew from industry sources and advisors, because of a lack of prior academic work. For overall opinions, work on media evaluation influenced scale 
Table 2 Customer Perceptions of Billboard Effects

\begin{tabular}{|c|c|c|c|c|c|c|}
\hline \multirow{2}{*}{$\begin{array}{l}\begin{array}{l}\text { Customer } \\
\text { Sample }\end{array} \\
(n=1,640)\end{array}$} & \multicolumn{2}{|c|}{$\begin{array}{l}\text { Noticed the } \\
\text { Billboards? }\end{array}$} & \multicolumn{3}{|c|}{$\begin{array}{l}\text { Mean Ratings (1-7) If Noticed } \\
(n=1,190)\end{array}$} & \multirow{2}{*}{$\begin{array}{l}\text { Opinion of } \\
\text { Billboards } \\
(n=1,640)\end{array}$} \\
\hline & No $\%$ & Yes \% & Increased Awareness & Informative & Influenced the Visit & \\
\hline New customer & 34.6 & 65.4 & 4.84 & 4.72 & 4.14 & 5.56 \\
\hline Returner & 20.5 & 79.5 & 4.48 & 4.88 & 3.80 & 5.64 \\
\hline All & 27.4 & 72.6 & 4.62 & 4.81 & 3.94 & 5.59 \\
\hline$\Phi$ or $t$ & $\Phi=.158$ & & $t=-2.972$ & $t=1.626$ & $t=-2.697$ & $t=1.068$ \\
\hline$p$ & $<.001$ & & .003 & .104 & .007 & .288 \\
\hline
\end{tabular}

construction (Dai Shij and Piron, 2002; Nowak, Cameron, and Krugman, 1993).

Scales regarding executives' evaluations of consumer views on billboards drew from previous research (Precision Marketing, 2006). Bipolar, 7-point scales (without labels for values 2-6) provided sufficient response options, good calibration, and visually even intervals to produce data at the interval level (Reips and Funke, 2008). Scale formats starting with negative rating options helped to counter possible social desirability or acquiescence bias (Krumpal, 2013), although these are lower risks in an anonymous survey of knowledgeable and experienced executives (See Appendix A).

Overall ratings for billboards were made alongside equivalent ratings for six other media, because these ratings constituted the dependent construct in the main model. This approach achieved greater ecological validity, as a more realistic overall mediaevaluation task. It also ensured that respondents considered their billboard ratings relative to competing media, in particular radio, television, Internet, newspapers, magazines, and yellow pages. Such comparative ratings were not feasible for all measures, because of executives' time constraints and declining response quality if surveys are long.

To minimize common method bias and the consistency motif (Podsakoff and Organ, 1986), the authors presented the evaluations of billboard attributes near the start of the survey, well separated from overall ratings of billboards. The executives also were not able to review their earlier pages of this electronic survey. Harman's test showed that variance explained by a single factor was well below the 50 percent guideline for common method bias concerns. In line with previous work (Podsakoff, Mackenzie, Lee, and Podsakoff, 2003), a more stringent test in the confirmatory factor analysis model found no differences greater than .20 between item loadings with and without a common latent factor.

The sampling frame was health-care marketing executives throughout the United States, drawn from a listing of 1,200 American Hospital Association-registered general hospitals. Telephone inquiries initially achieved 576 relevant contacts, all with media-buying involvement. Most of the hospitals had used billboards, but, to avoid selection bias, that was not a sampling criterion. Responses to the Internet survey from 263 hospitals (22 incomplete) achieved a 45.6 percent (41.8 percent) response rate, around the mean rate for management surveys (Mellahi and Harris, 2016). The usable sample of 241 was sufficient for the planned analyses (Hair, Black, Babin, and Anderson, 2010). This sample consisted of experienced and mostly senior executives (See Table 1).

\section{RESULTS}

\section{Study 1: Consumer Evaluations of Billboard Attributes}

Although the urgent-care centers were active users of billboard advertising, not everyone visiting the facilities likely noticed the billboards. In this study, 72.6 percent of respondents had noticed the billboards (See Table 2); the survey did not address questions specific to the campaign to the remaining 27.4 percent. It is important to note that 79.5 percent of returning customers had noticed the billboards, compared with 65.4 percent of new customers $(\Phi=$ $.158, p<.001$; See Table 2).

To compare indications of effects on new (action-stage) and returning (retention-stage) customers, the authors examined levels and comparisons on four salient measures (See Table 2). New customers naturally are more likely to perceive that billboards increased their awareness of the facility, $t(1045.39)=-2.974, p$ $=.003$. A more important finding is the level of perceived effect among returners. In this and possibly many other competitive markets, the reminder effect of billboards was effective also for returners. This is probably particularly important in situations in which patronage usually is less frequent, because advertising helps to replace the reminder effects of frequent usage.

In terms of information conveyance, returning customers considered the billboards slightly but not significantly more informative than did the new customers. Important here in strategic terms is the finding that both categories of customer tended to find the billboards informative. This reflects that existing customers also noted information about new facilities or services, required reminding and updating about facilities, opening times, and so on. 
Levels of influence were around the midpoint of this scale. Although new customers declared higher levels of billboards' influence than returning customers, a large proportion of returning customers also reported billboard influence, which suggests valuable retention effects. Organizations also need to consider many other factors that combine to drive customer patronage of medical-service facilities (Thomas, 2014), including word of mouth, reasonable prices (Gilbert, Lumpkin, and Dant, 1992), and prior experiences in the case of returning customers (Bopp, 1990).

Antagonism toward a medium can have adverse consequences, both for image of the advertiser and for advertisement effectiveness. All respondents could offer overall opinions of billboards as not relating to any specific campaign. Among new customers, 72.4 percent expressed a positive view of billboards (5-7 on the scale), not significantly different from 76.9 percent of returners. Few respondents (5.6 percent and 4.8 percent, respectively) indicated negative views (1-3 on the scale).

\section{Study 2: Managers' Evaluations of Billboard Capabilities}

Billboard Attributes. To evaluate the views of experienced marketing managers, the researchers asked respondents to rate billboards on 14 attributes (See Table 3). Each of the first eight of these attributes appears in at least some of the advertising-effects models. Among these, the highest rated items predictably were the preaction stage effects, which reflect conventional beliefs. These beliefs may influence executives' use of tracking studies measuring brand or advertisement awareness, which potentially reinforces some managers' assumptions that billboards are mainly about awareness. (For discussions of tracking techniques, see Harrison, 2013; Vaughan et al., 2016; Wilson and Casper, 2016).

Of the standard deviations for the first eight attributes, those for customer retention and customer loyalty were the largest, with lower means. This points to more diverse views regarding postpurchase effects, which were not always associated with billboards and also are beyond the scope of the existing AIDA model. On the basis of bivariate correlations at this stage, these action and postaction effects also influenced overall ratings of billboards $(p<.001)$.

To counter possible acquiescence bias, the researchers offered respondents more response options to indicate negative (1-3) or neutral (4) responses. More than one-third of executives indicated that billboards influenced prospective customers (37.8 percent) and existing customers (37.8 percent). More than a quarter of respondents went further in suggesting that billboards increased customer retention (28.2 percent) and loyalty (27.0 percent), which indicates belief in the reinforcement roles of billboards among a proportion of marketing executives.
Table 3 Managers' Ratings of Billboard Attributes

\begin{tabular}{llll}
\hline & & \multicolumn{3}{l}{$\begin{array}{l}\text { Ratings for Billboards (1-7) and } \\
\text { Correlations with Overall Rating for } \\
\text { Billboards }(\boldsymbol{p}<\mathbf{. 0 0 1})\end{array}$} \\
\cline { 2 - 4 } Media Attributes & $\mathbf{M}$ & SD & Pearson $\boldsymbol{r}$ \\
\hline 1. Being noticed & 5.07 & 1.236 & .536 \\
2. Create awareness & 5.16 & 1.197 & .556 \\
3. Generate interest & 4.71 & 1.290 & .642 \\
4. Create desire & 4.10 & 1.371 & .627 \\
5. Influence prospects & 4.15 & 1.297 & .502 \\
6. Influence customers & 4.06 & 1.348 & .487 \\
7. Customer retention & 3.72 & 1.406 & .492 \\
8. Customer loyalty & 3.66 & 1.457 & .537 \\
\hline 9. Cost & 3.80 & 1.306 & .499 \\
10. Creative potential & 4.79 & 1.749 & .453 \\
11. Lead time & 4.10 & 1.590 & .309 \\
\hline 12. Customer remembers & 4.75 & 1.290 & .557 \\
13. Helpful to customers & 4.39 & 1.299 & .548 \\
14. Nonintrusive & 4.26 & 1.311 & .467 \\
\hline
\end{tabular}

Principal-components analysis of the eight effect scales examined dimensionality of responses, producing two components based on the eigenvalue $<1$ criterion (See Appendix B ). These provided a clear division between beliefs regarding preactionstage capabilities and those at subsequent stages. The authors plotted the two principal components (See Figure 1) to depict the loadings of each billboard capability. This provided additional empirical insights into perceived positioning and proximities of these capabilities, with progression from the awareness and interest effects through to those concerned with influencing action and beyond to retention.

To achieve greater ecological validity in both the survey and the analyses, the researchers asked managers to rate billboards on media-management issues that they would evaluate when selecting advertising media (See Table 3). Among these factors, cost had a fairly neutral mean and a slightly higher correlation coefficient than the other two media-management issues. Lead time also had a near-neutral mean and, in bivariate terms, the lowest level of apparent influence on overall evaluations of billboards. Creative potential was rated most favorably among the three media-management issues and, on the basis of the correlations, was second to costs for influencing managers' overall evaluations of billboards.

Managers also must take into account customers' perception of the medium in general as well as the specific messages and images conveyed. The majority of managers considered that their customers remember billboards, find them helpful, and generally do 


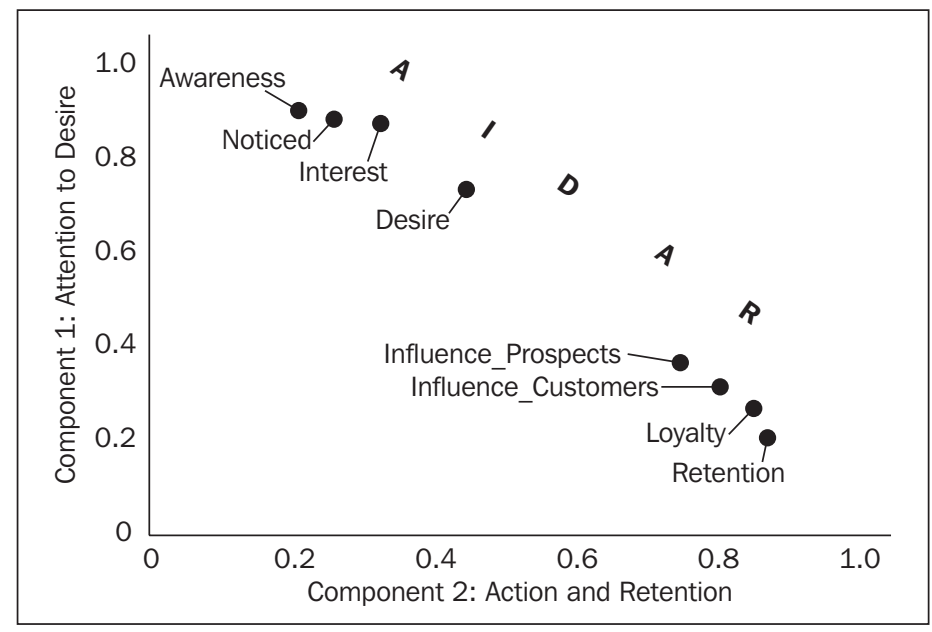

Figure 1 Evaluations of Billboard Functions-Components Plot

not see them as intrusive. Overall ratings for billboards occurred alongside equivalent ratings for six other media. This approach was intended to achieve ecological validity, as a more realistic media-evaluation task, and to ensure that respondents considered their overall billboard ratings relative to competing media -in particular radio, television, Internet, newspapers, magazines, and yellow pages.

Measurement Model. The authors needed to test whether evaluations of influence and retention effects contributed significantly toward managers' overall ratings of billboards as a medium, having taken into account their well-established preaction-stage effects. The impact scale comprised Items 1-3 from the list of media attributes (See Table 3; $\alpha=.883$ ). The influence scale comprised Items $6-8(\alpha=.847)$. The media issues scale included media selection criteria that did not directly measure effects on customer attitudes and behavior (Items 9-11; formative index). A benefits for consumers scale reflected management evaluations of billboards' direct utility for consumers (Items 12-14; $\alpha=.794$ ).

Confirmatory factor analysis assessed the overall fit of the measurement model and also facilitated further tests for common method bias, convergent validity, and discriminant validity. The fit statistics (normed fit index $=.957$, comparative fit index $=.984$ [criterion $>.90]$, and root-mean-square error of approximation $=$ .049 [criterion < .070]) all were well within accepted guidelines for model fit (Hair et al., 2010). The Fornell and Larcker test (Fornell and Larcker, 1981) provided a robust approach to testing discriminant validity (Voorhees, Brady, Calantone, and Ramirez, 2016), with each square root of average variance extracted greater than any interconstruct correlation.

The authors used multiple regression to evaluate the relative power of each of these constructs in predicting managers' overall appraisals of billboards (See Table 4). The impact scale achieved
TABLE 4 Factors Explaining Managers' Ratings: Multiple Regression

\begin{tabular}{lllll}
\hline Measure & $\boldsymbol{\beta}$ & $\boldsymbol{p}$ & $\boldsymbol{t}$ & VIF \\
\hline Impact scale & .353 & .000 & 5.022 & 2.641 \\
Influence scale & .165 & .005 & 2.804 & 1.816 \\
Benefits for consumers & .250 & .001 & 3.420 & 2.843 \\
Media issues index & .107 & .045 & 2.036 & 1.465 \\
\hline
\end{tabular}

Note: Analysis of variance: $\mathrm{F}(4,234)=63.173, p<.001$; adjusted $R^{2}=.554$. $\mathrm{VIF}=$ variance inflation factor.

the highest standardized beta weight, which reflects the conventional view on billboards primarily generating awareness and interest. The scale of management's perceived benefits to customers also contributed strongly, with the second highest beta. More important, the influence scale, which included action through to retention, also was highly significant, with the third strongest and significant $(p=.005)$ beta weight. Media-management issues correlated with overall ratings of billboards at the bivariate level, but that effect became more marginal when analyzed in conjunction with evaluations of billboard capabilities.

Multicollinearity was not a problem in this model, because all variance inflation factors were below 3.0. Adding five control variables in hierarchical regression mode tested whether managers' individual characteristics influenced these results. Respondents' age, gender, education, and years of media-buying experience did not have significant effects, nor did the proportion of the organization's advertising budget allocated to billboards. The authors consequently did not report these hierarchical regression results in detail.

\section{DISCUSSION}

\section{Managerial Implications}

There are strong indications from both the consumer and management studies that billboards are useful across the hierarchy of effects. Traditional management assumptions that billboards are mainly awareness and interest builders (Taylor et al., 2006) may be more a limitation of their typical usage rather than potential capabilities. Typical deployment goals for billboards can reinforce beliefs that billboards primarily serve to attract attention to products or facilities, especially among new consumers. Emphasis on tracking billboards' power to generate short-medium-term recall and awareness further reinforces these views. Managers and researchers thus may neglect the potential opportunities for billboards to reinforce intention and commitment among existing as well as new customers.

Theories and effects models in the fields of consumer behavior and social marketing highlight the importance of postaction 
reinforcement and retention, yet marketing practitioners and researchers seem less likely to consider these potential roles for billboards. Policy researchers have not neglected the reinforcement roles of billboards, where billboards may help to perpetuate harmful consumption patterns. It is implausible that billboards reinforce only negative behaviors, and the current studies show some recognition of the reinforcement and potential retention roles in positive marketing contexts.

These study findings also have wider implications for theories of advertising effects, some of which suggest hierarchical progressions. Although subject to criticisms over the years (e.g., Weilbacher, 2001), models such as AIDA remain influential and useful to advertisers, other marketers, and educators. Such models generally omit postpurchase and reinforcement roles of advertising, however, which reflects their origins in a selling-oriented era. The authors' work thus responds to the call to continue efforts to validate hierarchy-of-effects models in the context of advertising and marketing communications (Barry, 2002).

The AIDA model has been in use for more than a century, appearing initially as AID, with the "A" for "action" added later. In the personal selling context, one author suggested the addition of an "S" to AIDA to reflect "satisfaction," although that defines too narrowly the postpurchase potentials of advertising (Sheldon, 1911). Other authors developed ATR to ATRN to include "nudging" (Barnard and Ehrenberg, 1997). Even the most influential models therefore have adapted to reflect evolving marketing emphases.

In generalized models, parsimony is important, although some authors have suggested five stages prior to action (Lavidge and Steiner, 1961), and others have further subdivided preaction stages in the TTM (e.g., Velicer et al., 1995). The suggestion to expand to AIDAR by adding "retention" thus retains parsimony while filling the serious gap in the model.

A related theoretical lens through which to evaluate potential effects on new versus existing customers is category involvement bias (Gordon, McKeage, and Fox, 1998). The elaboration-likelihood model depicts higher and lower involvement routes toward persuasion (Petty and Cacioppo, 1986); the former typically include more stages in the journey toward purchase. This provides further indication that no single model can reflect fully or perfectly every type of decision, whether relating to advertising effects or other aspects of human behavior. Evolution of the TTM is also instructive in that people may not pass through all stages in all circumstances (Martin, Velicer, and Fava, 1996) and that relapse to earlier stages can occur.

In summary, therefore, the case for extending AIDA to AIDAR is as follows:
- Both AIDA and ATR have provided valuable frameworks for managers, researchers, and educators, yet all generalizations have limitations.

- Models can reflect the marketing emphases of their time. AIDA originated in the selling era, and ATR originated at a time of heightened interest in reinforcement, retention, and loyalty.

- The limitation of AIDA in not pointing to postaction stages and associated opportunities is seriously at odds with modern marketing practices.

- With the arrival of abundant sales and loyalty data, ATR addresses the postaction processes yet lacks some of the preaction stages of the AIDA, TTM, and CAC models.

- Marketers have not lost interest in consumers' interests and desires; they have access now to diverse data types to understand more fully consumers' purchasing journeys.

- Models require extension occasionally to fill gaps or to reflect changes in marketing emphasis. AIDA evolved from its original AID, whereas ATR(N) added "nudge" to the model.

- The early suggestion to add "S" for "satisfaction" highlighted a gap in AIDA, although that suggestion came in a personal selling context (Sheldon, 1911).

- From another field of human-behavior research, the TTM suggests stages of change inclusive of both pre- and postaction stages.

- Developments in the TTM recognize different transition routes that do not involve all stages necessarily and that accept "relapses" to earlier stages.

- The number and sequence of purchase stages vary with involvement in the purchase, relating to factors such as product role, price, life span, and purchase frequency.

- By combining the strengths of AIDA and ATR, AIDAR offers a more complete and more flexible model while retaining parsimony.

- The current study offers support from consumer and management studies but invites further research in other industries, media, and countries using diverse methods.

\section{Extensions and Limitations}

These studies were limited to the United States, one large service sector, and organizations large enough to have a specialist marketing function. Findings require testing more widely across other organization types and sectors. Researchers also could seek opportunities to use longitudinal data to estimate billboard effects on later stage behavioral outcomes, beyond initial patronage. Researchers could explore links between raised brand or category salience (Miller and Berry, 1998) among existing customers and managerially important advertising effects. Experimental 
techniques and technologies also could help researchers to explore how advertising content influences (re)patronage.

There is also a need to address executives' choices of methods to evaluate billboard effects and how these choices both affect and are influenced by perceptions of billboards' capabilities. Billboards will continue to offer new research opportunities as digital panels increase in number, adding a higher-tech image, enabling differentiation by time and occasions, and minimizing lead times. Although passersby cannot turn off billboards, billboards are less intrusive than Internet and mobile advertisements. They rely on their ability to capture the interest of passersby, so they could become more distinctive and attractive, both to consumers and to managers. Billboards also may stimulate web access, enabling voluntary and therefore nonintrusive web communications on the basis of interest initiated by the billboard.

Although this investigation provides both consumer and expert practitioner perspectives, it also highlights further opportunities for academic and industry researchers to explore the potential of billboards across the broader hierarchy of effects. Such research endeavors also would contribute to reappraisal of traditional advertising-effects hierarchy models, building on the suggested extension of the AIDA hierarchy to AIDAR. This reflects contemporary emphasis on postpurchase reinforcement, retention, and relationship building while also recognizing the continued interest in consumers' journeys to purchase.

\section{ABOUT THE AUTHORS}

John L. FortenberRy, JR. is chair of the James K. Elrod Department of Health Administration, James K. Elrod Professor of Health Administration, and professor of marketing in the School of Business at Louisiana State University Shreveport. He also serves as vp of marketing strategy and planning at Willis-Knighton Health System. His work has appeared in leading journals, including the Journal of Business Research and BMC Health Services Research.

Peter J. McGoldrick (corresponding author) is professor of retailing at the University of Manchester, United Kingdom. He has more than 200 research publications, including in the Journal of Retailing, Harvard Business Review, as well as Retail Marketing and other textbooks. He founded and directed the Retail Research Forum, a longterm industry-university collaboration, and served as a governor of the Academy of Marketing Science.

\section{REFERENCES}

Altman, D. G., C. Schooler, and M. D. Basil. "Alcohol and Cigarette Advertising on Billboards." Health Education Research 6, 4 (1991): 487-490.
Ambler, T. "Persuasion, Pride and Prejudice: How Ads Work." International Journal of Advertising 19, 3 (2000): 299-315.

Andreasen, A. R. Marketing Social Change: Change Behavior to Promote Health, Social Development, and the Environment. San Francisco: Jossey-Bass, 1995.

Barnard, N., and A. S. C. Ehrenberg. "Advertising: Strongly Persuasive or Nudging?" Journal of Advertising Research 37, 1 (1997): 21-32.

BARRY, T. E. "The Development of the Hierarchy of Effects: An Historical Perspective." Current Issues and Research in Advertising 10, 1-2 (1987): 251-295.

Barry, T. E. "In Defense of the Hierarchy of Effects: A Rejoinder to Weilbacher." Journal of Advertising Research 42, 3 (2002): 44-47.

Barry, T. E., and D. J. Howard. "A Review and Critique of the Hierarchy of Effects in Advertising." International Journal of Advertising 9, 2 (1990): 121-135.

Bergkvist, L., and J. R. Rossiter. "The Predictive Validity of Multiple-Item versus Single-Item Measures of the Same Constructs." Journal of Marketing Research 44, 2 (2007): 175-184.

Berkowitz, D., A. Allaway, and G. D'Souza. "The Impact of Differential Lag Effects on the Allocation of Advertising Budgets across Media." Journal of Advertising Research 41, 2 (2001): 27-36.

Bhargava, M., and N. Donthu. "Sales Response to Outdoor Advertising." Journal of Advertising Research 39, 4 (1999): 7-18.

Bhargava, M., N. Donthu, and R. Caron. "Improving the Effectiveness of Outdoor Advertising." Journal of Advertising Research 34, 2 (1994): 46-55.

Bleier, A., and M. Eisenbeiss. "The Importance of Trust for Personalized Online Advertising." Journal of Retailing 91, 3 (2015): 390-409.

Bopp, K. D. "How Patients Evaluate the Quality of Ambulatory Medical Encounters: A Marketing Perspective." Journal of Healthcare Marketing 10, 1 (1990): 6-15.

Colley, R. H. Defining Advertising Goals for Measured Advertising Results. New York: Association of National Advertisers, 1961.

Cramphorn, S. "How to Use Advertising to Build Brands: In Search of the Philosopher's Stone." International Journal of Market Research 48, 3 (2006): 255-276.

Dai Shij, T., and F. Piron. "Advertising Agencies and Advertisers' 
Perceptions of Internet Advertising." International Journal of Advertising 21, 3 (2002): 381-397.

Donthu, N., J. Cherian, and M. Bhargava. "Factors Influencing Recall of Outdoor Advertising." Journal of Advertising Research 33, 3 (1993): 64-72.

Ducoffe, R. H. "How Customers Assess the Value of Advertising." Journal of Current Issues and Research in Advertising 17, 1 (1995): 1-18.

Ehrenberg, A. S. C. "Repetitive Advertising and the Consumer." Journal of Advertising Research 14, 2 (1974): 25-34. (Reprinted in Journal of Advertising Research 14, 2 [2000]: 39-48.)

Ehrenberg, A. S. C., N. Barnard, R. Kennedy, and H. Bloom. "Brand Advertising as Creative Publicity." Journal of Advertising Research 42, 4 (2002): $7-18$.

Elliott, M. T., and P. S. Sреск. "Consumer Perceptions of Advertising Clutter and Its Impact across Various Media." Journal of Advertising Research 38, 1 (1998): 29-41.

Fitts, R. L., and W. C. Hewett. "Utilizing the Before After with Control Group Experimental Design to Evaluate an Outdoor Advertising Campaign." Journal of Advertising 6, 1 (1977): 26-39.

Fornell, C., and D. F. LARCKer. "Evaluating Structural Equation Models with Unobservable Variables and Measurement Error." Journal of Marketing Research 18, 1 (1981): 39-50.

Fortenberry, J. L., and P. J. McGoldrick. “The Receptiveness of Black Americans to Outdoor Advertising." Journal of Business Research 64, 6 (2011): 586-593.

Frison, S., M. G. Dekimpe, C. Croux, and P. De Maeyer. "Billboard and Cinema Advertising: Missed Opportunity or Spoiled Arms?" International Journal of Research in Marketing 31, 4 (2014): 425-433.

Gilbert, F. W., J. R. Lumpkin, and R. P. Dant. "Adaptation and Customer Expectations of Health Care Options." Journal of Health Care Marketing 12, 3 (1992): 46-55.

Gilly, M. C., J. L. Graham, M. F. Wolfinbarger, and L. J. Yale. "A Dyadic Study of Interpersonal Information Search." Journal of the Academy of Marketing Science 26, 2 (1998): 83-100.

Gordon, M. E., K. McKeage, and M. A. Fox. “Relationship Marketing
Effectiveness: The Role of Involvement." Psychology \& Marketing 15, 5 (1998): 443-459.

Ha, L., and B. R. Litman. "Does Advertising Clutter Have Diminishing and Negative Returns?" Journal of Advertising 26, 1 (1997): 31-42.

Hackbarth, P., B. Silvestri, and W. Cosper. "Tobacco and Alcohol Billboards in 50 Chicago Neighborhoods: Market Segmentation to Sell Dangerous Products to the Poor." Journal of Public Health Policy 16, 2 (1995): $213-230$

Hair, J. F., W. C. Black, B. J. Babin, and R. E. Anderson. Multivariate Data Analysis, 7th ed. Upper Saddle River, NJ: Prentice Hall, 2010.

Hammer, P., E. Riebe, and R. Kennedy. "How Clutter Affects Advertising Effectiveness." Journal of Advertising Research 49, 2 (2009): 159-163.

Harrison, F. "Digging Deeper Down into the Empirical Generalization of Brand Recall: Adding Owned and Earned Media to Paid-Media Touchpoints." Journal of Advertising Research, 53, 2 (2013): 181-185.

Havlena, W. J., and J. Graham. "Decay Effects in Online Advertising: Quantifying the Impact of Time Since Last Exposure on Branding Effectiveness." Journal of Advertising Research 44, 4 (2004): 327-332.

Hewett, W. C. "What One Little Showing Can Do." Journal of Advertising Research 12, 5 (1972): 29-30.

Kim, E., S. Kim, Y. YeH, and S. M. Chor. "Exploring the Antecedents of Advertising Avoidance on Online Video Sites." In American Academy of Advertising Conference Proceedings. Minneapolis, MN: American Academy of Advertising, 2011.

KING, K. W., and S. F. TinKham. "The Learning and Retention of Outdoor Advertising." Journal of Advertising Research 29, 6 (1989-1990): 47-51.

Klerkx, M., and L. Van Meurs. "Processing Outdoor Posters: Product and Brand Recognition in a Split of a Second." In International Advertising and Communication. Current Insights and Empirical Findings, S. Diehl and R. Terlutter, eds. Wiesbaden, Germany: Deutscher Universitäts Verlag, 2006.

Krumpal, I. “Determinants of Social Desirability Bias in Sensitive Surveys: A Literature Review." Quality \& Quantity 47, 4 (2013): 2015-2047.

Lavidge, R. C., and G. A. Steiner. "A Model for Predictive Measurement of Advertising Effectiveness." Journal of Marketing 25, 6 (1961): 59-62.

Martin, R. A., W. F. Velicer, and J. L. Fava. “Latent Transition Analysis 
to the Stages of Change for Smoking Cessation." Addictive Behaviors 21, 1 (1996): 67-80.

Mellahi, L., and L. C. Harris. "Response Rates in Business and Management Research: An Overview of Current Practice and Suggestions for Future Direction." British Journal of Management 27, 2 (2016): 426-437.

Miller, S., and L. Berry. "Brand Salience versus Brand Image: Two Theories of Advertising Effectiveness." Journal of Advertising Research 38, 5 (1998): $77-82$.

Mrtchell, A. “Advertisers, Face It, Your Consumers Hate You." (2012, March 29). Retrieved from the Campaign website: http://www.campaignlive.co.uk/ article/alan-mitchell-advertisers-face-it-consumers-hate/1124059

Moriarty, S., N. D. Mitchell, and W. D. Wells. Advertising and IMC: Principles and Practice, 10th ed. Boston: Pearson, 2015.

Naik, P. A., K. Peters, and K. Raman. "Heterogeneous Response Functions in Advertising." Arbeitspapiere des Lehrstuhls für Innovation, Neue Medien und Marketing, Institut für Betriebswirtschaftslehre, Universität Kiel, 2008. Retrieved from the Econstor website: https://www.econstor.eu/ handle/10419/27679

Nowak, G. J., G. T. Cameron, and D. M. Krugman. "How Local Advertisers Choose and Use Advertising Media." Journal of Advertising Research 33, 6 (1993): 39-49.

Osborne, A. C., and R. Coleman. "Outdoor Advertising Recall: A Comparison of Newer Technology and Traditional Billboards." Journal of Current Issues and Research in Advertising 30, 1 (2008): 13-30.

Outdoor Advertising Association of America. (2016). "Facts and Figures." Retrieved from https://oaaa.org/AboutOOH/Factsamp;Figures.aspx

Petty, R. E., and J. T. Caciopro. "The Elaboration Likelihood Model of Persuasion." Advances in Experimental Social Psychology 19 (1986): 123-205.

Podsakoff, P. M., and D. W. Organ. "Self-Reports in Organizational Research: Problems and Prospects." Journal of Management 12, 4 (1986): $531-544$.

Podsakoff, P. M., S. B. Mackenzie, J. Lee, and N. P. Podsakoff. "Common Method Biases in Behavioral Research: A Critical Review of the Literature and Recommended Remedies." Journal of Applied Psychology 88, 5 (2003): 879-903.

Precision Marketing. "PM Study Tracks Marketer versus Public Attitudes." Precision Marketing 18, 38 (2006): 3.
Prochaska, J. O., C. C. Diclemente, and J. C. Norcross. "In Search of How People Change: Applications to Addictive Behaviors." American Psychologist 47, 9 (1992): 1102-1114.

ReIPs, U. D., and F. FunKe. "Interval Level Measurement with Visual Analogue Scales in Internet-Based Research: Vas Generator." Behavior Research Methods 40, 3 (2008): 699-704.

Rossiter, J. R. "The C-OAR-SE Procedure for Scale Development in Marketing." International Journal of Research in Marketing 19, 4 (2002): 305-335.

Scenic America. (2017). “The Truth about Billboards." Retrieved from http:// www.scenic.org/billboards-a-sign-control/the-truth-about-billboards

Seyedghorban, Z., H. Tahernejad, and M. J. Matanda. "Re-Inquiry into Advertising Avoidance on the Internet: A Conceptual Replication and Extension." Journal of Advertising 45, 1 (2016): 120-129.

Sheldon, A. F. The Art of Selling. Chicago: Sheldon School, 1911.

Smit, E. G., and P. C. Neijens. "Segmentation Based on Affinity for Advertising." Journal of Advertising Research 40, 4 (2000): 35-43.

Solomon, M. R. Consumer Behavior: Buying, Having, and Being, 12th ed. Boston: Pearson, 2017.

Steinberg, B. “Repeat Ad Nauseam: TV Spots Risk Driving Consumers Away." Advertising Age 79, 44 (2008): 1-10.

Strong, E. K. The Psychology of Selling. New York: McGraw-Hill, 1925.

Taylor, C. R., and G. R. Franke. "Business Perceptions of the Role of Billboards in the U.S. Economy." Journal of Advertising Research, 43, 2 (2003): 150-161.

Taylor, C. R., G. R. Franke, and H.-K. Bang. "Use and Effectiveness of Billboards." Journal of Advertising 35, 4 (2006): 21-34.

Thомаs, R. K. Marketing Healthcare Services. Chicago: Health Administration Press, 2014.

Truong, Y., and G. Simmons. "Perceived Intrusiveness in Digital Advertising: Strategic Marketing Implications." Journal of Strategic Marketing 18, 3 (2010): 239-256.

Vaughan, K., V. Beal, and J. Romaniuk. “Can Brand Users Really Remember Advertising More than Nonusers? Testing an Empirical Generalization across Six Advertising Awareness Measures." Journal of Advertising Research 56, 3 (2016): 311-320.

Velicer, W. F., S. L. Hughes, J. L. Fava, and J. O. Prochaska. “An Empirical 
Typology of Subjects within Stage of Change." Addictive Behaviors 20, 3 (1995): 299-320.

Vespe, F. "High Tech Billboards: The Same Old Litter on a Stick." Journal of Public Policy and Marketing 16, 1 (1997): 176-179.

Voorhees, C. M., M. K. Brady, R. Calantone, and E. Ramirez. “Discriminant Validity Testing in Marketing: An Analysis, Causes for Concern, and Proposed Remedies." Journal of the Academy of Marketing Science 44, 1 (2016): 119-134.

Weilbacher, W. M. “Point of View: Does Advertising Cause a 'Hierarchy of Effects'?" Journal of Advertising Research 41, 6 (2001): 19-26.
Wilson, R. T., and J. Casper. "The Role of Location and Visual Saliency in Capturing Attention to Outdoor Advertising: How Location Attributes Increase the Likelihood for a Driver to Notice a Billboard Ad." Journal of Advertising Research 56, 3 (2016): 259-273.

Wilson, R. T., and B. D. Till. “Effects of Outdoor Advertising: Does Location Matter?" Psychology E Marketing 28, 9 (2011): 909-933.

Yoo, B., N. Donthu, and S. Lee. "An Examination of Selected Marketing Mix Elements and Brand Equity." Journal of the Academy of Marketing Science 28, 2 (2000): 195-211.

Young, E. "Visibility Achieved by Outdoor Advertising." Journal of Advertising Research 24, 4 (1984): 19-21.

\section{Appendix A Measurement Scales}

\section{MEASUREMENT ITEMS FROM STUDY 1: CONSUMER SURVEY AT URGENT CARE CENTERS}

1. Have you noticed [company] [facility name] billboards in the [cities] area? No Yes (if No, skip to question 5)

2. To what degree did billboards influence your visit to this clinic? No influence at all (7 evenly spaced boxes to) Major influence

3. To what degree did billboards increase your awareness of this clinic? No increase at all (7 evenly spaced boxes to) Major increase

4. To what degree did you view billboards as informative?
Not informative at all
(7 evenly spaced boxes to)
Very informative

5. What is your overall opinion of billboards? Very negative
(7 evenly spaced boxes to)
Very positive

6. Is this your first visit to ? No Yes

Classification questions regarding age, gender, income, and education levels.

\section{MEASUREMENT ITEMS FROM STUDY 2: NATIONAL SURVEY OF MARKETING/ADVERTISING EXECUTIVES} Assessments of Possible Effects:

How much do you disagree or agree that billboard advertisements ...

- Are noticed by target markets

- Increase awareness within target markets

- Generate interest within target markets

- Create desire within target markets

- Influence existing customers to extend patronage

- Influence prospective customers toward patronage

- Increase customer loyalty
(7 evenly spaced clickers to)

(same scale as above) (same scale as above) (same scale as above) (same scale as above) (same scale as above) (same scale as above) 


\section{Assessments of Other Media Management Issues:}

Based on the following attributes, how would you rate billboards?

- Cost

- Creative potential

Very Poor

- Lead time

\section{Executives' Views on How Customers Perceive Billboards:}

How much do you disagree or agree that billboards are generally ...

- Remembered by customers

- Helpful to customers

- Seen as non-intrusive by customers
Disagree Strongly

Very Negative

- Television

- Internet

- Newspapers

- Magazines

- Billboards

- Yellow Pages
(7 evenly spaced clickers to)

(same scale as above)

(same scale as above)
(7 evenly spaced clickers to) (same scale as above) (same scale as above)
Very Good

Agree Strongly

(7 evenly spaced clickers to)

(same scale as above)

(same scale as above)

(same scale as above)

(same scale as above)

(same scale as above)

(same scale as above)

To achieve measurement at the interval level, scales have labels only for values 1 and 7 . Intermediate points 2 thru 6 on scales have numbers only, to achieve equal intervals both numerically and visually.

Classification questions regarding gender, age, seniority, years buying media, and percentage media spend. See Table 1 (Study 2 ) for aggregated categories and summary of distributions.

Appendix B Evaluations of Billboard Functions: Principal Components

\begin{tabular}{lll}
\hline \multirow{2}{*}{$\begin{array}{l}\text { Managers' Evaluations of } \\
\text { Billboard Capabilities }\end{array}$} & \multicolumn{2}{l}{$\begin{array}{l}\text { Principal-Components } \\
\text { Analysis Components }\end{array}$} \\
\cline { 2 - 3 } 7-point scales) & Preaction & Action-Retention \\
\hline Billboards are noticed & .876 & .259 \\
Increase awareness & .895 & .210 \\
Generate interest & .868 & .325 \\
Create desire & .733 & .449 \\
Influence prospective customers & .360 & .752 \\
Influence existing customers & .312 & .807 \\
Increase customer retention & .203 & .874 \\
Increase customer loyalty & .264 & .858 \\
\hline
\end{tabular}

Note: Kaiser-Meyer-Olkin statistic $=.843$; oblimin rotation; variance explained $=$ $79.1 \%$. 